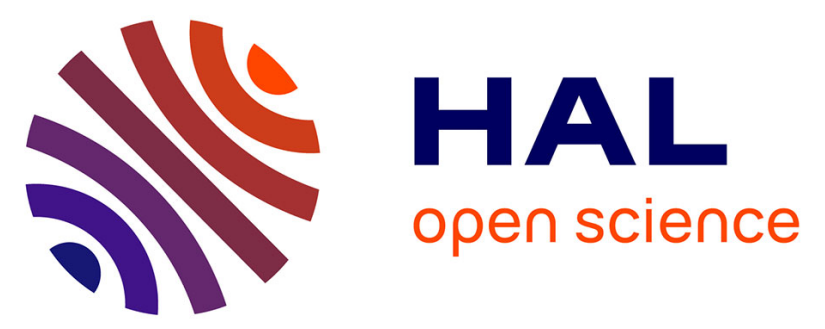

\title{
Effects of occupational exposure to poorly soluble forms of beryllium on biomarkers of pulmonary response in exhaled breath of workers in machining industries
}

\author{
Anca Radauceanu, Michel Grzebyk, Jean-Louis Edmé, Nathalie
}

Chérot-Kornobis, Davy Rousset, Mathieu Dziurla, Virginie de Broucker, Guy

Hedelin, Annie Sobaszek, Sébastien Hulo

\section{To cite this version:}

Anca Radauceanu, Michel Grzebyk, Jean-Louis Edmé, Nathalie Chérot-Kornobis, Davy Rousset, et al.. Effects of occupational exposure to poorly soluble forms of beryllium on biomarkers of pulmonary response in exhaled breath of workers in machining industries. Toxicology Letters, 2016, 263, pp.26-33. 10.1016/j.toxlet.2016.10.013 . hal-01414392

\author{
HAL Id: hal-01414392 \\ https://hal.science/hal-01414392
}

Submitted on 12 Dec 2016

HAL is a multi-disciplinary open access archive for the deposit and dissemination of scientific research documents, whether they are published or not. The documents may come from teaching and research institutions in France or abroad, or from public or private research centers.
L'archive ouverte pluridisciplinaire HAL, est destinée au dépôt et à la diffusion de documents scientifiques de niveau recherche, publiés ou non, émanant des établissements d'enseignement et de recherche français ou étrangers, des laboratoires publics ou privés.

\section{(ㅇ)(1) $\$$}

Distributed under a Creative Commons Attribution - NonCommercial - NoDerivatives $\mid 4.0$ 
3

4 Anca RADAUCEANU ${ }^{1 *}$, Michel GRZEBYK ${ }^{1}$, Jean-Louis EDME ${ }^{2,3}$, Nathalie CHÉROT-KORNOBIS ${ }^{2,4}$, 5 Davy ROUSSET ${ }^{1}$, Mathieu DZIURLA ${ }^{1}$, Virginie DE BROUCKER ${ }^{2,3}$, Guy HEDELIN ${ }^{1}$, Annie SOBASZEK ${ }^{2,4}$,

6 Sébastien HULO 2,3

$7 \quad{ }^{1}$ Institut National de Recherche et de Sécurité pour la prévention des accidents de travail et des

8 maladies professionnelles (INRS), F-54519 Vandœuvre-lès-Nancy, France

$9{ }^{2}$ Univ. Lille, EA 4483 - IMPECS - IMPact de l'Environnement Chimique sur la Santé humaine, F-59000 10 Lille, France

$11{ }^{3} \mathrm{CHU}$ Lille, Service des Explorations Fonctionnelles Respiratoires, F-59000 Lille, France

$12{ }^{4} \mathrm{CHU}$ Lille, Service de Médecine du Travail du Personnel Hospitalier, F-59000 Lille, France

\section{E-mail addresses}

15 AR: anca.radauceanu@inrs.fr

16 MG: michel.grzebyk@inrs.fr

17 JLE: jledme@univ-lille2.fr

18 NCK: nathalie.cherot@univ-lille2.fr

19 DR: davy.rousset@inrs.fr

20 MD: $\underline{\text { mathieu.dziurla@inrs.fr }}$

21 VDB: virginie.debroucker@chru-lille.fr

22 GH: guy.hedelin@inrs.fr

23 AS: annie.sobaszek@univ-lille2.fr

24 SH: sebastien.hulo@univ-lille2.fr 

47

Full postal addresses

1) Institut National de Recherche et de Sécurité pour la prévention des accidents de travail et des maladies professionnelles (INRS) : 1, rue du Morvan, CS 60027, 54519 Vandœuvre-lèsNancy Cedex, France

2) Université de Lille, EA $4483: 1$, place de Verdun, 59000 Lille, France

3) Centre Hospitalier Universitaire de Lille, Service des Explorations Fonctionnelles Respiratoires : 2, avenue Oscar Lambret, 59037 Lille Cedex, France

4) Centre Hospitalier Universitaire de Lille, Service de Médecine du Travail du Personnel Hospitalier : 2, avenue Oscar Lambret, 59037 Lille Cedex, France

\section{*Corresponding author: Anca RADAUCEANU}

E-mail: anca.radauceanu@inrs.fr

Phone number: + 33 (0) 383509809

Fax number: + 33 (0) 383502015

Address: Département Epidémiologie en entreprise, INRS, 1 rue du Morvan, 54519 Vandœuvre-lèsNancy Cedex, France 6 48 9 0 1 53 


\section{ABSTRACT}

Objective: To analyze the effects of occupational exposure to poorly soluble forms of beryllium (Be) on biomarkers of pulmonary inflammation using exhaled breath condensate (EBC) in workers employed in machining industries.

Methods: Twenty machining operators were compared to 16 controls. The individual exposure to Be was assessed from the work history with several indices of exposure calculated on the basis of taskexposures matrices developed for each plant using historical air measurements. Clinical evaluation consisted in a medical questionnaire, measurements of biomarkers in EBC (tumor necrosis factor alpha (TNF- $\alpha$ ), total nitrogen oxides (NOx)), measurement of the fraction of exhaled nitric oxide (FeNO) and resting spirometry. Adjusted multiple linear regressions were used to study the effect of the exposure to Be on inflammatory biomarkers.

Results: Levels of TNF- $\alpha$ and NOx in EBC were not statistically different between exposed and controls. We found a statistically significant relationship between levels of TNF- $\alpha$ in EBC and both index of cumulative exposure and duration of exposure to Be. No other statistically significant relationships were found between exposure to Be and pulmonary response.

Conclusion: Our results suggest that machining-related exposure to Be is related to pulmonary inflammation involving TNF- $\alpha$. These findings must be confirmed by larger studies.

Keywords: beryllium; exhaled breath condensate; tumor necrosis factor alpha; occupational exposure; machining.

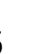

\section{7} 8 79 80 


\section{HIGHLIGHTS}

- We studied the pulmonary inflammatory response to low exposure to beryllium (Be)

- TNF- $\alpha$ and nitrogen reactive species were assayed in exhaled breath condensate (EBC)

- Cumulative exposure to Be was correlated with TNF- $\alpha$ in EBC of machining operators

- No relationship between exposure to Be and nitrogen reactive species was found

- Low air exposure to Be is associated with pulmonary inflammation involving TNF- $\alpha$

8

89

90

(1)

2

3

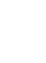

6

8

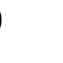




\section{INTRODUCTION}

118 Beryllium (Be) is a naturally occurring metal whose physical and mechanical properties are much 119 sought-after in high technology industries, especially in the aeronautics, aerospace, energy, 120 electrical, electronic and medical sectors. The Be industry produces 3 primary poorly soluble forms of 121 Be: metallic Be, alloys of Be and oxides of Be. Exposure to Be and its compounds has been known to cause chronic beryllium disease (CBD), so called berylliosis, a long latency granulomatous disorder resembling sarcoidosis, that requires a prior Be sensitization phase (BeS) and primarily affects the lung (Balmes et al., 2014). The immunological reactions observed in affected individuals are Bespecific hypersensitivity responses involving CD4+ T-lymphocytes, production of T helper 1 (Th1) type cytokines and the subsequent generation of granulomatous inflammation in the lungs (Muller et al., 2011). Tumor necrosis factor-alpha (TNF- $\alpha$ ), a Th1-type cytokine, may exert effects on cell recruitment at site of inflammation and induce granulomatous structures (Semenzato et al., 2000). Despite an increased understanding of the pathogenesis of BeS and CBD, little is known about relationships between external exposure, internal exposure and early respiratory effects. Once Be is deposited in a region of the respiratory tract, its chemical form and solubility are important exposure factors to pulmonary injuries (Stefaniak et al., 2004). Relatively insoluble Be compounds as well as copper-beryllium alloys were associated with development of CBD even in workers exposed at airborne concentrations of Be below the occupational exposure limit of $2 \mu \mathrm{g} \cdot \mathrm{m}^{-3}$ (Schuler et al., 2005). Thus, poorly soluble species are thought to be responsible for local effects whereas soluble compounds are readily taken up and excreted with urine.

The use of a local matrix to monitor target tissue dose and effects occurring in the respiratory tract can be suggested when exposure to pneumotoxic substances occurs by inhalation (Mutti and Corradi, 2006). Exhaled breath condensate (EBC) represents one of these promising matrices. EBC collection is a completely noninvasive method for obtaining samples that reflect airway lining fluid composition through non-volatile substances (Kubáň and Foret, 2013). Biomarkers of local inflammation and oxidative stress - cytokines, nitric-oxide-related products, arachidonic acid metabolites, hydrogen peroxide, aldehydes - were reported as potential sensitive endpoints when identifying early biochemical changes in the airways of workers exposed to various pneumotoxic subtances (Chérot-Kornobis et al., 2012). Nitric oxide (NO) is an important mediator involved in several physiological processes that induces respiratory tract injuries via the interaction of NO with reactive oxygen species resulting in reactive nitrogen intermediates (Sugiura et al., 2011; Robbins et al., 2000). NO-related products, which are found in EBC, are formed in the airways by oxidation of NO in nitrogen oxides (NOx, namely nitrite and nitrate) (Kubáň and Foret, 2013). 
We recently reported that it was possible to quantify beryllium in the EBC of workers exposed mainly to water soluble forms of beryllium in a primary aluminum production plant (Hulo et al., 2016). We also shown that concentrations of $\mathrm{Be}$ in $\mathrm{EBC}$ and cumulative beryllium exposure index were significantly correlated.

To our knowledge, there have been no published data on exhaled biomarkers to assess respiratory tract effects in workers exposed to beryllium yet. Thus, the aim of the present study was to analyze the effects of occupational exposure to poorly soluble forms of Be on pulmonary inflammation using $\mathrm{EBC}$ in workers employed in machining industries.

\section{MATERIALS AND METHODS}

\subsection{Study population}

We conducted an exposed-control study in a population of 20 workers exposed to poorly soluble forms of $B$ and 16 control subjects. Exposed subjects worked in three French plants $(A, B$ and $C)$ that machined:

- low beryllium alloys (copper - beryllium (Cu-Be) alloys with beryllium content $2 \%$ for plant $A$ and $3 \%$ for plant $B$ ). Eight exposed workers were recruited from plants $A$ and $B$

- high beryllium alloy with aluminum (Al-Be) (beryllium content $62 \%$ ) and beryllium metal for plant C. Twelve exposed workers were recruited from plant C.

Machining operations within the plants consist mainly in lathe work, milling, grinding, deburring, filling, polishing, sanding and electrospark machining. Plants were identified from a French assessment survey of exposure associated with occupational use of Be and its compounds ((Vincent et al., 2009) and recruited on a voluntary basis of their management boards. Within each recruited plant, we identified workrooms and workstations with potential exposure to beryllium. All the operators working in these workrooms and workstations were proposed to participate to the study. The voluntary participants were informed about the protocol study and signed an informed and free consent form before enrollment.

Controls were enrolled at the same plants as the exposed subjects and were recruited on the statement of no current or previous Be exposure. We checked during onsite plant visits that controls' activities were disconnected from Be-exposed working areas and were performed in specific buildings far from Be-exposed working areas. Seven controls were recruited from plants $A$ and $B$, and nine controls from plant $C$.

\subsection{Study protocol}

The study protocol was approved by the French national data protection commission and by the East ethics committee on protection of persons. All the subjects were recruited in 2010-2011 and answered a interviewed questionnaire in two parts: 
- A medical questionnaire to assess medical history and treatment, in particular respiratory health and smoking habits. We used the questionnaire of the European Community for Steel and Coal on respiratory symptoms (Minette, 1989).

- A questionnaire to gather occupational history, focusing on the type, the duration and frequency of Be exposed operations as well as occupational exposure to other pneumotoxicants such as aluminum, titan, zirconium, welding fumes, copper, cobalt, antimony, iron, silica, asbestos, oil mist, nickel, chrome, refractory ceramic fibers, chlorine, solvents.

Then we collected the following samples in that order:

- collection of EBC samples

- measurement of fraction of exhaled nitric oxide $\left(\mathrm{F}_{\mathrm{e}} \mathrm{NO}\right)$

- $\quad$ spirometric measurements

All clinical data were collected during the workshift.

\subsection{Assessment of exposure to beryllium}

Workers' exposure to Be was related to machining tasks performed on alloys $\mathrm{Cu}-\mathrm{Be} 2-3 \%$ in plants $\mathrm{A}$ and $\mathrm{B}$, and on alloy $\mathrm{Al}-\mathrm{Be} 62 \%$ and Be metal in plant $\mathrm{C}$. Beryllium exposed operations and tasks were recorded for each of the three plants based on information collected during the plants visits and workstation observations before the subjects' recruitment. For each Be-exposing task, exposure to Be was assessed using historical plant hygiene data issued from measurements campaigns that were performed in the 3 plants between 1998 and 2011. Using historical air measurements, task-exposure matrices were developed for each plant allowing the estimation of a level of exposure to Be for relevant operations.

Inhalable fraction of aerosols taken in personal and area samples were collected at a flow rate of 1 or 2 L.min ${ }^{-1}$ (GilAir тм pumps, Gilian Instrument Corp., West Calwell, N.J.) using 37-mm diameter closed-face cassette (Merck Millipore Billerica, MA, USA) with a 4-mm diameter orifice containing a quartz fiber filter or a cellulose ester membrane (Merck Millipore Billerica, MA, USA). Once the sample had been taken, the internal walls of the cassettes were rinsed with $3 \mathrm{~mL}$ of nitric acid. Three milliliters of sulfuric acid and the rinse liquid was added to the membrane and subsequently mineralized by microwave. Volume was then adjusted to $25 \mathrm{~mL}$ with ultrapure HNO3 $2 \%$. According to French standards, analyses were performed either by ICP-MS following NF X 43-275 before 2010 (NF X 43-275, 2002) or ISO 30011 after 2010 (ISO 30011, 2010) or by electrothermal atomic absorption spectrometry. Overall these air sampling protocols are validated to quantify exposure levels of beryllium above $1 \mathrm{ng} \cdot \mathrm{m}^{-3}$.

Several indices of exposure were determined for each subject on the basis of the job histories:

- "total years" is the duration of beryllium exposed jobs defined as the total number of years of potential beryllium exposure (in years) 
- "weighted Be exposure duration" (WBED), calculated by summing the products of the duration of each exposed task and the frequency of the task through all work history (in years) (Benke et al., 2000)

- "cumulative Be exposure index" (CBEI), which represents the lifetime sum of the products of the duration, frequency and beryllium exposure level for each beryllium exposed task (in ng.m $\mathrm{m}^{-3}$.years)

- " current Be exposure index" represents the sum of products of the beryllium level and frequency for each task performed at the time of interview (in ng. $\mathrm{m}^{-3}$ )

- "alloy Be content" with 3 levels: controls, low Be content and high Be content. Exposed subjects from plants A and B were classified in "low Be content" (8 workers), exposed subjects from plant C were classified in "high Be content" (12 workers).

Subjects were also questioned on current and past co-exposure to known pneumotoxic species other than Be. Information on the number of pneumotoxic species, the duration and the frequency of associated operations in workplace were collected. Subsequently, a cumulative co-exposure index (CEI) was calculated for each subject as above.

\subsection{Assessment of pulmonary response}

\section{Collection of $E B C$}

The exhaled breath condensate (EBC) samples were collected at $-4^{\circ} \mathrm{C}$ using a Transportable Unit for Research on Biomarkers Obtained from Disposable Exhaled Condensate Collection Systems (TURBODECCS) device (ItalChill, Parma, Italy) according to the latest recommendations (Horvath et al., 2005). A disposable device consisting in a mouthpiece connected to a one-way aspiration valve, a saliva trap and a collection tube allowed to collect at least $2 \mathrm{ml}$ of EBC during about 40 minutes of tidal breathing through the mouthpiece. Collected volumes of EBC (median(IQR)) were not statistically different (4.1 $\mathrm{ml}$ (2-5.5) in exposed group vs $4.25 \mathrm{ml}$ (3.6-4.9) in control group).

All EBC samples were stored and transported at $-20^{\circ} \mathrm{C}$ and finally stored at $-80^{\circ} \mathrm{C}$. All biomarkers measurements in $\mathrm{EBC}$ were performed altogether at the end of the recruitment. Analysis of $E B C$

The concentration of TNF- $\alpha$ was measured using an enzyme-linked immunosorbent assay (ELISA kit Human TNF- $\alpha$ Ultra sensible, Invitrogen, DO $450 \mathrm{~nm}$ ). Our limit of detection was $0.09 \mathrm{pg} / \mathrm{ml}$. The average of the coefficient of variation for intra-assay variability was $9.5 \%(S D=8.5 \%)$.

The total nitrogen oxides $\left(\mathrm{NO}_{\mathrm{x}}\right.$, namely nitrite and nitrate) were assayed by the Griess method (Griess Reagent Kit, Invitrogen, Cergy Pontoise, France) with spectrophotometric detection by two measurements: at first, nitrite was measured by the Griess reaction and then nitrate was reduced enzymatically to nitrite by nitrate reductase (Sigma, St. Quentin Fallavier, France). The concentration measured represents the sum of the nitrites and nitrates initially present in the EBC. Nitrate content 
of EBC was calculated based on the difference between both measurements. Our limit of detection (LOD) was $2 \mu \mathrm{M}$. Intra-assay variability expressed as mean (SD) of coefficients of variation was $4.9 \%(4.7)$.

Fraction of exhaled nitric oxide $\left(F_{e} N O\right)$ measurement FeNO was measured by chemiluminescent detection of FeNO (ENDONO $8000^{\circledR}$, SERES) according to the international recommendations (ATS/ERS Recommendations, 2005). Subjects were seated and nose clips were not used. After deep inspiration, NO concentrations were measured during controlled expiration, at the first stable $\mathrm{F}_{\mathrm{e}} \mathrm{NO}$ plateau for at least three seconds (FeNO variations < $10 \%$ or $1 \mathrm{ppb}$ ). $\mathrm{F}_{\mathrm{e}} \mathrm{NO}$ was recorded as mean of two FeNO measurements at $50 \mathrm{~mL} / \mathrm{s}$ expiratory flow. Spirometric measurements

Pulmonary function tests were performed according to the 2005 guidelines of the European Respiratory Society (Miller et al., 2005) using the portable SpiroDyn'R spirometer (Dyn'R society, Muret, France). Standard measures of pulmonary function were collected including forced vital capacity (FVC), forced expiratory volume in the first second $\left(\mathrm{FEV}_{1}\right), \mathrm{FEV}_{1} / \mathrm{FVC}$ ratio, and forced expiratory flow at $25 \%$ and $75 \%$ of vital capacity (FEF25-75). Data were expressed as ratios of observed/predicted values using reference values of the Global Lung Function Initiative (Quanjer et al., 2012)

\subsection{Statistical analysis}

Descriptive statistics of exposure parameters as well as clinical and biological data were computed for both exposed and control groups. The log-transformed values were used for the FeNO analysis. The comparisons of means of quantitative parameters were performed using Student $t$-tests and the comparisons of qualitative parameters using Chi-square test. The correlation between two continuous parameters was assessed with Spearman's correlation coefficient.

Descriptive statistics of exposure parameters as well as clinical and biological data were computed for both exposed and control groups. The log-transformed values were used for the FeNO analysis. The comparisons of means of quantitative parameters were performed using Student $t$-tests and the comparisons of qualitative parameters using Chi-square test. The correlation between two continuous parameters was assessed with Spearman's correlation coefficient. Relationships between exposure to $\mathrm{Be}$ and health outcomes were analysed using multiple linear regressions. These outcomes were the log-transformed exhaled biomarkers (TNF- $\alpha$ and NOx in EBC, FeNO) and pulmonary function parameters. Independent variables included adjustment factors and exposure indices. Each index of exposure to beryllium was tested separately in different models. For quantitative indices the logarithm of the index (to which was added one so the transformed index is zero for unexposed workers) was used as independent variable. Both exposed workers and controls were included in the analyses. 
The adjustment factors were selected based on their potential effects on airway inflammation. Multiple linear regressions were adjusted for history of pulmonary disease (presence of asthma, nasal polyposis, chronic obstructive pulmonary disease, emphysema, diffuse interstitial fibrosis), smoking status (smokers/ex-smokers/non-smokers), gender, age, and co-exposure index. We tested interactions between adjustment factors but they were not statistically significant. The statistical analyses were performed with STATA software (v. 14, Statacorp LP). A two-sided significance level of 0.05 was chosen for all tests.

3. RESULTS

\subsection{General characteristics of the study population}

General characteristics are shown in Table 1. There was no significant difference in clinical data (respiratory history and symptoms) between controls and exposed subjects. There were more women in control group $(p=0.01)$. All spirometric indices were above the lower limit of normal and there were no statistically significant differences between exposed group and controls.

\subsection{Assessment of beryllium exposure}

Exposure matrices were developed for each plant in order to assign levels of exposure to each task. Altogether, 36 specific job tasks were defined for individual exposure reconstruction as following:

- Plant A - eight tasks with exposure to alloy copper-beryllium 2\%: lathe work, milling, sanding, electrospark machining, welding, polishing, grinding, manual filling

- Plant B - five tasks with exposure to alloy copper-beryllium 3\%: deburring with a clipping tool, etching, wet machining, polishing, assembling

- Plant C - twenty-three tasks with exposure to beryllium metal and alloy aluminumberyllium 62\%, performed with different machines and belonging to the following

Due to the confidentiality agreements with the companies, the results of beryllium exposure levels for each task cannot be provided here.

The highest Be concentration was measured in plant C on personal air samples collected in 1998 in Be machining workroom $\left(3 \mu \mathrm{g} \cdot \mathrm{m}^{-3}\right)$. All the other airborne concentrations of beryllium were below the current French occupational exposure limit value of $2 \mu \mathrm{g} \cdot \mathrm{m}^{-3}$. In contrast, a quarter of these concentrations were above the limit value of $0.05 \mu \mathrm{g} \cdot \mathrm{m}^{-3}$ proposed by the American Conference of

322 Governmental Industrial Hygienists (ACGIH, 2010).

323 The different indices of exposure were calculated for exposed subjects and controls and are presented according to alloy Be content (Table 2). 
Occupational co-exposures reported by the workers were the following: copper, oil mist, iron, silica, chrome, welding fumes and solvents in plants A and B; aluminum, iron, titan, solvents and oil mist in plant C.

Cumulative co-exposure index was twofold higher in plants with low Be alloys exposure (plant A and plant B) than in the plant with high Be alloys exposure (plant C).

\subsection{Exhaled biomarkers}

The measurements of exhaled biomarkers in controls and exposed are presented in Table 3 according to alloy Be content.

NOx and TNF- $\alpha$ were quantified in all samples of EBC. Levels of exhaled biomarkers of exposed subjects were slightly higher than those of controls but these differences were not statistically significantly different. Measurements of NOx in EBC and FeNO were not statistically significantly correlated (Spearman's correlation coefficient was $0.05(\mathrm{p}=0.79)$ ). Also, EBC biomarkers NOx and TNF- $\alpha$ were not correlated (Spearman's correlation coefficient was $-0.25(p=0.14)$ ) as well as TNF- $\alpha$ in EBC and FeNO (Spearman's correlation coefficient was $0.07(p=0.67))$.

EBC biomarkers TNF- $\alpha$ and NOx were not correlated with any of spirometric parameters (data not shown).

\subsection{Relationships between cumulative exposure and exhaled biomarkers}

The results of the multiple linear regressions are shown in Table 4.

The adjusted models showed that higher are the weighted Be exposure duration (WBED) or the cumulative Be exposure index (CBEI), higher are the TNF- $\alpha$ levels in EBC. The corresponding coefficients of determination for these models are 0.19 and 0.20 , respectively. These results are unchanged when adjusting on pack-years during lifetime instead of smoking status (data not shown). Neither NOx in EBC nor FeNO levels were statistically significantly related to indices of beryllium exposure.

Likewise, spirometric measurements were not statistically significantly related to parameters of exposure to Be (data not shown).

\section{DISCUSSION}

To our knowledge, this pilot study is the first that analyzes exhaled biomarkers in active workers exposed to low atmospheric concentration of different poorly soluble Be species. Firstly, we found that the levels of NOx and TNF- $\alpha$ in EBC of subjects currently exposed were slightly higher than those of controls but not statistically different. Secondly, we have shown a statistically significant relationship between cumulative exposure to beryllium and the level of TNF- $\alpha$ in EBC. Finally, we have not found relationships between exposure to beryllium and nitrogen reactive species, for both volatile (FeNO) and nonvolatile (NOx in EBC) nitrogen intermediates. 
All exposed subjects of our study were employed in machining industries and were exposed to poorly soluble forms of beryllium. Machining beryllium releases a large amount of particles of small size namely more than $50 \%$ of the particles in the breathing zone $<10 \mu \mathrm{m}$ size and $30 \%<0.6 \mu \mathrm{m}$ - that are likely to result in increased lung deposition compared to greater particles (Martyiny et al., 2000). Hoover et al (1990) has reported that milling processes, compared to sawing, produces Be particles with a smaller mass median aerodynamic diameter and a greater proportion of particles $<5 \mu \mathrm{m}$ in diameter. Very small (i.e., $\leq 2.5 \mu \mathrm{m}$ ) particles penetrate to the deep lung and are associated with increased risk of CBD. Respirable size particles with poorly soluble Be that deposit in alveolar region of the lung are rapidly engulfed by macrophages where they undergo dissolution and slow clearance, resulting in longer Be retention, greater opportunity for interaction with the immune system and formation of granulomas and chronic inflammation, which is characteristic of CBD (Stefaniak et al., 2006). The insoluble molecules in the epithelial lining fluid have an alveolar residence time that is potentially very long, unlike water-soluble particles that can be phagocytized or cross the alveolar epithelium through transcytosis (Oberdörster, G. et al., 2007).

The historical Be air measurements used in our study were rather low, and, consequently, the values of calculated indices of exposure. Most of air Be concentrations were below the limit value of $0.05 \mu \mathrm{g} \cdot \mathrm{m}^{-3}$ proposed by the ACGIH and all but one were below the current French occupational exposure limit value of $2 \mu \mathrm{g} . \mathrm{m}^{-3}$. These levels are consistent with those reported in French industry (Vincent et al., 2009).

Individual exposure were then assessed using task-exposure matrices specific to each plant based on historical air samples measurements of similar tasks. By summing the cumulative exposures of a worker over all tasks worked within a job title, the task-exposure matrix was shown to address the variability of exposure within the job title and reduce possible exposure misclassification using a jobexposure matrix (Benke et al., 2000). However the assessment of Beryllium exposure levels is affected by the relative scarcity of available historical data; this may reduce the ability to detect a relationship between the estimated cumulative levels and the biomarkers of pulmonary response. Other types of exposure parameters were calculated for each subject, some of which frequently reported such as "total years" (Harper et al., 2014), others calculated ad-hoc such as "current Be exposure index" or "weighted duration" of exposure to Be. These exposure parameters may be more robust than the cumulative exposure as they are not based on the task-exposure matrices. Furthermore, they are less subject to the recall bias common in the retrospective assessment of the occupational exposure. Lastly, differences in Be content and alloys between plants A, B and C were taken in account in our study by regrouping plants and their workers according to the alloy Be content. 
In the present study, the spirometric indices were adjusted for age, size and sex by recent GLI equations 2012 (Quanjer et al., 2012). Indeed, a recent study demonstrated that the equations GLI 2012 provided a better fit in a French population, particularly among women (Hulo et al., 2016). We did not find significant difference in pulmonary function indices between exposed and controls. None of the exposed subjects showed an obstructive ventilatory disorder or decrease in vital capacity that could be suspected restrictive ventilatory disorder. These results can be partly explained by the low occupational exposure of the exposed group.

In contrast to spirometric or imaging testing which often indicate late and irreversible lung pathological process related to pneumotoxic species in workplace, the study of inflammatory and oxidative biomarkers in EBC which are likely to reflect the composition of the airway-lining fluid may be useful to assess early lung pathobiology accompanying or preceding inflammation (Mutti and Corradi, 2006).

TNF- $\alpha$ is a cytokine known to mediate and cause inflammatory reactions. It is noteworthy that the development of granulomatous inflammation in the lungs of patients with chronic beryllium disease (CBD) is associated with activation and accumulation of CD4+ T cells (Fontenot at al., 2002). T cells are activated in the presence of Be antigen and release proinflammatory Th1-type cytokines, mostly TNF- $\alpha$, interferon-gamma and IL-2. Experimental studies of immunotoxicity following inhalation exposure in mice showed different pattern of cytokine secretion related to the chemical form of beryllium (Müller et al., 2011). Overall, in this latter study, inhalation of Be metal and Be oxide produces greater pulmonary toxicity than other forms. Although workers of our study were exposed to a low Be concentration, we have shown a relationship between duration and cumulative exposure to poorly soluble Be compounds and the level of TNF- $\alpha$ in EBC. In other words, being occupationally exposed on a full time basis during 10 years to an airborne Be concentration of $0.05 \mu \mathrm{g} \cdot \mathrm{m}^{-3}$ (the occupational exposure limit proposed by ACGIH in 2010) is associated to an increase of 75\% in TNF- $\alpha$ in EBC. However, this result may be interpreted cautiously and, at the present time, we cannot speculate on the clinical relevance of this result. Our data suggest that TNF- $\alpha$ measured in EBC could mediate a nonspecific early step inflammation in workers exposed to low levels of Be by inhalation. As note, in the granulomatous disorder sarcoidosis resembling berylliosis, the release of Th1 cytokines represents the earliest step in the series of events that lead to formation of pulmonary granulomas (Semenzato et al., 2000). Whether this inflammatory status could predispose to a progression to sensitization or berylliosis could not be addressed in this pilot study.

In our study, TNF- $\alpha$ was detectable in the EBC of all subjects, as in previous studies in chronic obstructive pulmonary disease (COPD) (Ko et al., 2009) but unlike in cleaning workers with asthma for which the detection rate was lower (30\%) (Viczaya et al., 2013). Values measured in our study were similar to those measured in other healthy population but were lower than those reported in 
sarcoidosis (3.37 pg.mL ${ }^{-1}$ ) and in systemic sclerosis patients (13.5 pg.mL ${ }^{-1}$ ) (Mohan et al., 2016; Edmé et al., 2008). As salivary contamination could occur in EBC sampling, it is worth noting that salivary influence on the cytokine assessment in EBC may be negligible (Ichikawa et al., 2007). Although FeNO is currently the most advanced airway inflammation marker in term of robustness, reproducibility and standardization of measurement (Kubáň and Foret, 2013), the nitrosative and oxidative stress assessed by non-volatile NOx exhibits satisfactory reproducibility and consistent stability and was largely reported in occupational settings (Chérot-Kornobis et al., 2012). Thus, nitrite concentration in EBC is significantly higher in workers exposed to chromium or welding fumes compared to controls (Murgia et al., 2006, Brand et al., 2010). We did not find correlation between the FeNO and NOx levels in our population, like a previous study which reported a lack of correlation in asthmatic patients (Chérot-Kornobis et al., 2011).

These results can be explained by the fact that NO could be metabolized in different products through multiple ways of the oxidative and nitrosative stress (Rahman et al., 2006, Chérot-Kornobis et al., 2011). We did not find any relation between the markers of oxidant or nitrosant stress measured in our study (NOx in EBC and FeNO) and the occupational exposure to beryllium.

\section{Limitations}

445 Our study concerns a small number of subjects. Our recruitment forecasts were based on the study 446 of Vincent et al. (Vincent et al., 2009) but recruitment of employees regularly exposed to beryllium was difficult as a consequence of the 2009 economic crisis. Moreover, industrial processes and specific regulations have evolved between the data published by Vincent and our recruitment campaign. In this study, workers were exposed to beryllium-containing alloys with different beryllium contents ranging from $2 \%$ to $100 \%$, and this heterogeneity of exposure leads to a cautious interpretation of the results. Unfortunately, beryllium sensitization blood test was not performed and we did not dispose of BeLPT status or personal medical data. The limited availability of laboratories assessing BeLPT in France and medical data confidentiality were the main reasons.

\section{CONCLUSION}

This pilot study reports several new findings relating biomarkers in EBC of workers in machining industries exposed to low levels of poorly soluble forms of Be. Taken together, the results suggest that machining-related exposure to beryllium seems to be associated to pulmonary inflammation involving TNF- $\alpha$. Larger studies are necessary to confirm these results.

\section{CONFLICT OF INTEREST}

460 The authors declare that they have no conflict of interest.

\section{FUNDING}

462 The study was funded by own funds of our institutions without external financial support. 


\section{ACKNOWLEDGMENTS}

The authors thank Mrs. M. Veillé and C. Bertrand (INRS, Département Epidemiologie en entreprise) for recruitment, logistics and data collection, the team of the Pollutant Metrology Department of INRS for the support on facilities recruitment and assays of exposure assessment, and all members of Lille University and Lille University Hospital who carried out laboratory analyses and provided scientific expertise. The authors thank staffs facilities, occupational physicians and all employees who participated in this study. We wish to express our gratitude to the staffs of French regional health insurance funds (CRAM) and their chemistry laboratories for their invaluable support.

\section{REFERENCES}

ACGIH, 2010. 2010 Threshold Limit Values (TLVs ${ }^{\circ}$ ) and Biological Exposures Indices (BEIs ${ }^{\circ}$ ) - Beryllium and Compounds. Cincinnati (USA), American Conference of Governmental Industrial Hygienists (ACGIH, accessed 29/11/2011), 245 p.

ATS/ERS, 2005. Recommendations for standardized procedures for the online and offline measurement of exhaled lower respiratory nitric oxide and nasal nitric oxide, 2005. Am. J. Respir. Crit. Care Med. 171, 912-930.

Balmes, J.R., Abraham, J.L., Dweik, R.A., Fireman, E., Fontenot, A.P., Maier, L.A., Müller-Quernheim, J., Ostiguy, G., Pepper, L.D., Saltini, C., Schuler, C.R., Takaro, T.K., Wambach, P.F., 2014. An official American Thoracic Society statement: diagnosis and management of beryllium sensitivity and chronic beryllium disease. Am. J. Resp. Crit. Care Med. 190, e34-59.

Benke, G., Sim, M., Fritschi, L., Aldred, G., 2000. Beyond the job exposure matrix (JEM): the task exposure matrix (TEM). Ann. Occup. Hyg. 44, 475-482.

Brand, P., Gube, M., Gerards, K., Bertram, J., Kaminski, H., John, A.C., Kuhlbusch, T., Wiemann, M., Eisenbeis, C., Winkler, R., Kraus, T., 2010. Internal exposure, effect monitoring, and lung function in welders after acute short-term exposureto welding fumes from different welding processes. J. Occup. Environ. Med. 52, 887-892.

Chérot, N., Hulo, S., Edmé, JL ., de Broucker, Matran, R., Sobaszek, A. 2011. Analysis of nitrogen oxides (NOx) in the exhaled breath condensate (EBC) of subjects with asthma as a complement to exhaled nitric oxide (FeNO) measurements: a cross-sectional study. BMC research notes, 4: 202 http://www.biomedcentral.com/1756-0500/4/202

Chérot, N., Hulo, S., de Broucker, V., Hassoun, S., Lepage, N., Edmé, JL., Sobaszek, A. 2012. Induced sputum, exhaled NO, and breath condensate in occupational medicine. J. Occup. Environ. Med. 54, 922-927.

Edme, J.L., Tellart, A.S., Launay, D., Neviere, R., Grutzmacher, C., Boulenguez, C., Labalette, M., Hachulla, E., Hatron, P.Y., Dessaint, J.P., Matran, R., Sobaszek, A., 2008. Cytokine concentrations in exhaled breath condensates in systemic sclerosis. Inflamm. Res. 57, 151-156.

Fontenot, A.P., Maier, L.A., Canavera, S.J., Hendry-Hofer, T.B., Boguniewicz, M., Barker, E.A., Newman, L.S., Kotzin, B.L., 2002. Beryllium skin patch testing to analyze T cell stimuation and granulomatous inflammation in the lung. J. Immunol. 168, 3627-3634.

Harber, P., Su J., Alongi, G., 2014. Exposure factors associated with chronic beryllium disease development in beryllium biobank participants. J. Occup. Environ. Med. 56, 852-856. 
Hulo S, Radauceanu A., Cherot-Kornobis N., et al., 2016. Beryllium in exhaled breath condensate as a biomarker of occupational exposure in a primary aluminium production plant. Int J Hyg Environ Health, 219, 40-47

Hulo, S., de Broucker, V., Giovannelli, J., Cherot-Kornobis, N., Nève, V., Sobaszek, A., Dauchet, L., Edmé, J.-L., 2016. Global Lung Function Initiative reference equations better describe a middle-aged, healthy French population than the European Community for Steel and Coal values. Eur. Respir. J. doi:10.1183/13993003.00606-2016

Hoover, M.D., Finch, G.L., Mewinney, J.A., Edson, A.F., 1990. Release of aerosols during sawing and milling of beryllium metal and beryllium alloys. Appl. Occup. Environ. Hyg. 5, 787-791.

Horváth, I., Hunt, J., Barnes, P.J., Alving, K., Antczak, A., Baraldi, E., Becher, G., van Beurden, W.J.C., Corradi, M., Dekhuijzen, R., Dweik, R.A., Dwyer, T., Effros, R., Erzurum, S., Gaston, B., Gessner, C., Greening, A., Ho, L.P., Hohlfeld, J., Jöbsis, Q., Laskowski, D., Loukides, S., Marlin, D., Montuschi, P., Olin, A.C., Redington, A.E., Reinhold, P., van Rensen, E.L.J., Rubinstein, I., Silkoff, P., Toren, K., Vass, G., Vogelberg, C., Wirtz, H., 2005. On behalf of the ATS/ERS Task Force on Exhaled Breath Condensate. Exhaled breath condensate: methodological recommendations and unresolved questions. Eur. Respir. J. 26, 523-548.

Ichikawa, T., Matsunaga, K., Minakata, Y., Yanagisawa, S., Ueshima, K., Akamatsu, K., Hirano, T., Nakanishi, M., Sugiura, H., Yamagata, T., Ichinose, M., 2007. Possible impact of salivary influence on cytokine analysis in exhaled breath condensate. Analytical Chemistry Insights 2, 85-92.

ISO 30011, 2010. Workplace air - Determination of metals and metalloids in airborne particulate matter by inductively coupled plasma spectrometry. International Organization for Standardization, Geneva, Switzerland.

Ko, F., Leung, T., Wong, G., NGgai, J., To K., Ng, S., Hui, D., 2009. Measurement of tumor necrosis factor- $\alpha$, leukotriene $B 4$, and interleukin 8 in the exhaled breath condensate in patients with acute exacerbations of chronic obstructive pulmonary disease. Int. J. Chron. Obstruct. Pulm. Dis. 4, 79-86.

Kubáň, P., Foret, F., 2013. Exhaled breath condensate: determination of non-volatile compounds and their potential for clinical diagnosis and monitoring. A review. Anal. Chim. Acta 805, 1-18.

Madl, A.K., Unice, K., Brown, J.L., Kolanz, M.E., Kent, M.S., 2007. Exposure-response analysis for beryllium sensitisation and chronic beryllium disease among workers in a beryllium metal machining plant. J. Occup. Environ. Hyg. 4, 2448-2466.

Martyny, J.W., Hoover, M.D., Mroz, M.M., Ellis, K., Maier, L.A., Sheff, K.L., Newman, L.S., 2000. Aerosols generated during beryllium machining. J. Occup. Environ. Med. 42, 8-18.

Miller, M.R., Hankinson, J., Brusasco, V., Burgos, F., Casaburi, R., Coates, A., Crapo, R.,

Enright, P., van der Grinten, C.P.M., Gustafsson, P., Jensen, R., Johnson, D.C., Maclntyre, N., McKay, R., Navajas, D., Pedersen, O.F., Pellegrino, R., Viegi, G., Wanger, J., 2005. Standardisation of spirometry. Eur. Respir. J. 26, 319-338.

Minette A., 1989. Questionnaire of the European Community for coal and steel (ECSC) on respiratory symptoms. Eur. Respir. J. 2, 165-177.

Mohan, N., Akter, R., Bryant, K., Herbert, C., Chow, S., Thomas, P.S., 2016. Exhaled breath markers of alveolar macrophage activity in sarcoidosis. Inflamm. Res. 65, 471-478, doi: 10.1007/s00011-0160929-y.

Muller, C., Salehi, F., Mazer, B., Bouchard, M., Adam-Poupart, A., Chevalier, G., Truchon, G., Lambert, J., Zayed, J., 2011. Immunotoxicity of 3 chemical forms of beryllium following inhalation exposure. Int. J. Toxicol. 30, 538-545. 
Murgia, N., Muzi,G., Dell'Omo, N., Montuschi, P., Melchiorri, D., Ciabattoni, G., 549 Abbritti, E.P., Orazi, N., Sapia, I.E., Abbritti, G., 2006. Induced sputum, exhaled breath condensate, 550 and nasal lavage fluid in electroplating workers exposed to chromium. Int. J. Immunopathol. 551 Pharmacol. 19(suppl), 67-71.

552 Mutti, A., Corradi, M., 2006. Recent developments in human biomonitoring: non-invasive assessment 553 of target tissue dose and effects of pneumotoxic metals. Med. Lav. 97, 199-206.

554 NF X 43-275, 2002. Qualité de l'air - Air des lieux de travail - Dosage d'éléments présents dans l'air 555 des lieux de travail par spectrométrie atomique. Association française de normalisation, Paris, France

556 Oberdörster, G., Oberdörster, E., Oberdörster, J., 2007. Concepts of nanoparticle dose metric and 557 response metric. Environ. Health Perspect. 115, A290.

558 Quanjer, P.H., Stanojevic, S., Cole, T.J., Baur, X., Hall, G.L., Culver, B.H., Enright, P.L., Hankinson, J.L., 559 Ip, M.S.M., Zheng, J., Stocks, J., ERS Global Lung Function Initiative, 2012. Multi-ethnic reference 560 values for spirometry for the 3-95-yr age range: the global lung function 2012 equations. Eur. Respir. 561 J. 40, 1324-1343. doi:10.1183/09031936.00080312

562 Rahman, I., Biswas, S.K., Kode, A., 2006. Oxidant and antioxidant balance in the airways and airways 563 diseases. Eur. J. Pharmacol. 533, 222-239.

564 Robbins, R.A., Hadeli, K., Nelson, D., Sato, E., Hoyt, J.C., 2000. Nitric oxide, peroxinitrite, and lower 565 respiratory tract inflammation. Immunopharmacology 48, 217-221.

566 Semenzato, G., Adami, F., Maschio, N., Agostini, C., 2000. Immune mechanisms in interstitial lung 567 diseases. Allergy 55, 1103-1120.

568 Schuler, C.R., Kent, M.S., Deubner, D.C., Berakis, M.T., McCawley, M., Henneberger, P.K., Rossman, 569 M.D., Kreiss, K., 2005. Process-related risk of beryllium sensitization and disease in a copper570 beryllium alloy facility. Am J Ind Med. 47, 195-205.

571 Stefaniak, A.B., Hoover, M.D., Day, G.A., Dickerson, R.M., Peterson, E.J., Kent, M.S., Schuler, 572 C., Breysse, P.N., Scripsick, R.C., 2004. Characterization of physicochemical properties of beryllium 573 aerosols associated with prevalence of chronic beryllium disease. J. Environ. Monit. 6, 523-532.

574 Stefaniak, A.B., Day, G.A., Hoover, M.D., Breysse, P.N., Scripsick, R.C., 2006. Differences in dissolution 575 behavior in a phagolysosomal simulant fluid for single-component and multi-component materials 576 associated with beryllium sensitization and chronic beryllium disease. Toxicol. In Vitro 20, 82-95.

577 Sugiura, H., Ichinose, M., 2011. Nitrative stress in inflammatory lung diseases. Nitric oxide 25, 138578144.

579 Vizcaya, D., Mirabelli, M., Orriols, R., Anto, J.M., Barreiro, E., Burgos, F., Arjona, L., Gomez, F., 580 Zock, J.P., 2013. Functional and biological characteristics of asthma in cleaning workers. Respir. Med. 581 107, 673-683.

582 Vincent, R., Catani, J., Creau, Y., Frocaut, A.M., Good, A., Goutet, P., Hou, A., Leray, F., André583 Lesage, M.A., Soyez, A., 2009. Occupational exposure to beryllium in French enterprises: A survey of 584 airborne exposure and surface levels. Ann. Occup. Hyg. 53, 363-372. 